\title{
Amelioration of Visual Display Terminal-induced Ocular Fatigue by Aqueous Extracts of Perilla frutescens var. acuta
}

\author{
Jaeyong Kim ${ }^{1}$, Hakjoon Choi ${ }^{1}$, Mi-Ri Kim ${ }^{1}$, Dooi-Ri Oh ${ }^{1}$, Yujin Kim ${ }^{1}$, Huwan Kang ${ }^{1}$, Kyeong-in Jeong ${ }^{2}$, \\ Geun-chang Ryu ${ }^{2}$, SangO Pan ${ }^{1}$, Chul-yung Choi ${ }^{1, *}$ \\ ${ }^{1}$ Jeonnam Institute of Natural Resources Research, Jangheung-gun, Jeollanamdo, South Korea \\ ${ }^{2}$ Department of Optometry and Optic science of Dongshin University, Naju, Jeollanamdo, South Korea \\ *Corresponding author: blockstar@hanmail.net
}

\begin{abstract}
In this study, we investigated the effects of Perilla frutescens var. acuta aqueous extract (PFA) on eyestrain using in vitro, ex vivo, and clinical tests. We confirmed the antioxidant activity of compounds present in the extract by using high-performance liquid chromatography. PFA contains antioxidant compounds such as rosmarinic acid, luteolin-7-O-glucuronide, and apigenin-7-O-glucuronide, and has been shown to inhibit reactive oxygen species generation in C2C12 muscle cells. In an ex vivo study, PFA inhibited the carbachol $(100 \mu \mathrm{M})$ induced contraction of ciliary muscle from rabbit eyeball. We then investigated the mechanism by which PFA caused muscle relaxation and found that it effectively increased cyclic GMP production and inhibited PDE5A activity, but did not affect the cyclic AMP pathway, in cultured human aortic smooth muscle cells. In addition, PFA (50, 100, and $200 \mu \mathrm{g} / \mathrm{mL}$ ) dose-dependently decreased basal intracellular calcium in smooth muscle cells and attenuated the endothelin-1-stimulated increase in intracellular calcium. Finally, we performed a clinical study to evaluate the effects of PFA on the near point of accommodation (NPA) after visual display terminal (VDT) work. Thirty participants were randomized to either PFA (500 mg/day) or placebo, and intake for one consecutive week. NPA was evaluated before and after $2 \mathrm{~h}$ of VDT work, and was found to be improved in the PFA-treated group. Thus, our findings show that PFA may ameliorate visual fatigue.
\end{abstract}

Keywords: perilla frutescens var. acuta, visual display terminal (VDT), visual fatigue, near point of accommodation, ciliary muscle

Cite This Article: Jaeyong Kim, Hakjoon Choi, Mi-Ri Kim, Dooi-Ri Oh, Yujin Kim, Huwan Kang, Kyeong-in Jeong, Geun-chang Ryu, SangO Pan, and Chul-yung Choi, "Amelioration of Visual Display Terminalinduced Ocular Fatigue by Aqueous Extracts of Perilla frutescens var. acuta." Journal of Food and Nutrition Research, vol. 5, no. 8 (2017): 553-561. doi: 10.12691/jfnr-5-8-4.

\section{Introduction}

Eye fatigue has been steadily increasing in recent years, with the growing use of visual display terminals (VDT) such as computers and smartphones $[1,2,3]$. The symptoms of eye fatigue include ocular pain, dry eye sensation, headache, dizziness, ghost images, eye pain, dryness, heavy eyelids, and blurred vision [4,5]. Recently, research conducted at the National Institute for Occupational Safety and Health (NIOSH) showed that over $50 \%$ of frequently VDTs users reported visual fatigue and other ocular problems associated with VDT use [6].

Some researchers reported oxidative stress as the cause of eye fatigue and various eye conditions [7]. Reactive oxygen species (ROS) produced in the crystalline lens induced eye strain [8]. Some studies have reported that certain natural plant-derived extracts, including bilberry, Haematococcus pluvialis, blackcurrant, and black soybean hull extracts, can ameliorate visual fatigue and exert antioxidant effects $[2,7,9]$. Antioxidant compounds have
Been shown to be effective in improving visual function $[7,10]$.

Visual fatigue is related to the accommodative ability of the eye to everyday activities [9]. Clinical studies have showed visual fatigue is closely associated with ophthalmic factors, which represents the accommodative ability of the eye such as the near point of accommodation (NPA) $[9,11,12]$. Accommodation provides the ability to change in focusing power controlled by the crystalline lens that during ciliary muscle contraction, thus allowing the eye to focus on near objects [13]. Eye fatigue is caused by the excessive use and resultant exhaustion of the ciliary muscle [14]. A decrease in the accommodative ability of the eye is caused by the loss of ciliary muscle function, which regulates the thickness of the lens $[15,16,17]$. The mechanism underlying ciliary muscle relaxation has been extensively studied in the search for drug therapies for the treatment of eye diseases [18]. Relaxation of ciliary smooth muscle is mediated by two mechanisms: cyclic AMP (cAMP)-dependent pathways, including prostaglandin receptor-mediated responses, and cyclic GMP (cGMP)-dependent pathways [19]. In general, increased cAMP and cGMP induces smooth muscle 
relaxation [20]. In addition, intracellular $\mathrm{Ca}^{2+}$ concentration $\left[\mathrm{Ca}^{2+}\right] i$ in smooth muscles is a major factor affecting the contraction of ciliary smooth muscle [20].

Perilla frutescens var. acuta is a traditional medicinal plant used in Asian countries, including Korea, China, and Japan, for treating symptoms such as depression, anxiety, allergies, bacterial and fungal infections, common cold, shivering fits, fever, chest pains, and cough $[21,22,23]$. The leaves of this plant are widely consumed in sushi, soups, and salads, as a spice and food colorant, and for garnishing [24]. Previous pharmacological studies have shown that $P$. frutescens var. acuta exerts antioxidant, anti-inflammatory, anti-allergic, anti-microbial, and antitumor effects $[25,26,27,28]$. In addition, studies have reported that flavonoids, phenolic acids, and anthocyanins were isolated from the leaves of $P$. frutescens [29]. Phenolic compounds in this plant extracts exhibit high antioxidant activity [24]. However, the effect of these compounds on visual fatigue has not yet been elucidated. To the best of our knowledge, this is the first study to report the effects of an aqueous extract of $P$. frutescens $v$ ar. acuta (PFA) on visual fatigue. We investigated the effects of PFA on of ROS generation in smooth muscle cells to confirm the antioxidant activity of its constituents, as well as its ability to cause relaxation in rabbit ciliary body muscle through the cGMP pathway. Finally, we performed a clinical study to determine the effect of PFA on NPA.

\section{Materials and Methods}

\subsection{Preparation of PFA Extract}

Dried leaves ( $3 \mathrm{~kg}$ ) were extracted in 10 volumes $(\mathrm{w} / \mathrm{v})$ of distilled water for $3 \mathrm{~h}$ at $100^{\circ} \mathrm{C}$ according to the method reported by Kim et al with slight modifications [30]. The process was repeated three times and the resulting filtrates were pooled, concentrated under reduced pressure at $40^{\circ} \mathrm{C}$, and lyophilized at $-50^{\circ} \mathrm{C}$ to obtain a solid reddish-brown residue (650 g).

\subsection{High-performance Liquid Chromatography (HPLC) Analysis for Identification of Phytochemical Composition}

HPLC analysis of PFA was performed using a YL 9100 HPLC system (Young Lin Instrument Co. Ltd., Korea) equipped with a binary pump (YL9111), UV/VIS detector (9120), and auto sampler (9150), and a Triart $C_{18}$ plus column $(250 \times 4.6 \mathrm{~mm}, 5 \mu \mathrm{m}$, YMC Co. Ltd.). The detection wavelength was set at $325 \mathrm{~nm}$ for water extract, luteolin-7-O-extract, apigenin-7-O-extract, and rosmarinic acid. The column thermostat was maintained at $35^{\circ} \mathrm{C}$.

Methanol and water (containing $0.1 \%$ formic acid) were used as the mobile phase $\mathrm{A}$ and $\mathrm{B}$, respectively. The elution profile was as follows: $0-10 \mathrm{~min}, 30 \% \mathrm{~A} ; 10-30 \mathrm{~min}$, 30-50\% A; 30-35 min, 60\% A; 35-40 min, 60-70\% A; 40-45 min, 70-100\% A; 45-53 min, 100\% A; 53-56 min, $100-30 \%$ A; $56-60 \mathrm{~min}, 30 \% \mathrm{~A}$. The flow rate was $1 \mathrm{~mL} / \mathrm{min}$, and the injection volume was $10 \mu \mathrm{L}$.

\subsection{Measurement of ROS Levels In Muscle Cells}

Mouse myoblast C2C12 cells (ATCC, Manassas, VA, USA) were maintained in Dulbecco's Modified Eagle Medium supplemented with $10 \%$ fetal bovine serum $\left(\right.$ GIBCO $^{\circledR}$; Life Technologies Co., Carlsbad, CA, USA), $100 \mathrm{units} / \mathrm{mL}$ of penicillin, and $100 \mu \mathrm{g} / \mathrm{mL}$ of streptomycin and maintained in a humidified cell incubator under an atmosphere of $5 \% \mathrm{CO}_{2}$ at $37^{\circ} \mathrm{C}$. The ROS levels inhibition activity in muscle cells of PFA was measured using the method reported by Kim et al [31]. Cells $\left(5 \times 10^{5}\right.$ cells $/ \mathrm{mL}$ of medium/well) were seeded in a 48-well plate and pretreated with PFA $(50,100$, and $200 \mu \mathrm{g} / \mathrm{mL})$ for $24 \mathrm{~h}$ prior to induction of stress by hydrogen peroxide $\left(\mathrm{H}_{2} \mathrm{O}_{2}, 200 \mu \mathrm{M}\right)$ and further incubation for $2 \mathrm{~h}$. Cell viability was measured by the 3-(4,5-dimethylthiazol-2-yl)-2,5-diphenyltetrazolium bromide (MTT) assay. To measure ROS levels, cells were washed twice with phosphate-buffered saline (PBS), lysed with $1 \%$ Triton $\mathrm{X}-100$ in PBS for 10 min at $37^{\circ} \mathrm{C}$, and stained with $10 \quad \mu \mathrm{M} \quad 2^{\prime}, 7^{\prime}$-dichlorodihydrofluorescein diacetate (DCFH-DA) for $30 \mathrm{~min}$ at room temperature in the dark. The cells were then washed twice with ice-cold PBS, and fluorescence intensity was examined using a fluorescence microscope (Olympus Optical, Japan) and measured using a microplate fluorometer (SpectraMax M2, Molecular Devices, Sunnyvale, CA) at excitation and emission wavelengths of 485 and $530 \mathrm{~nm}$, respectively.

\subsection{Relaxation of Rabbit Ciliary Muscle}

\subsubsection{Measurement of Isomeric Tension of Ciliary Muscle}

Female clean rabbits (2.4-2.7 kg) were purchased from Samtako (Osan, Korea) and were anesthetized with an intramuscular injection of Zoletil-Rompun mixture (1:2). The isolation of ciliary muscle was performed according to the method reported by Matsumoto et al with slight modifications [19]. The eyes were immediately enucleated and placed in Krebs solution at $4^{\circ} \mathrm{C}\left(\mathrm{CaCl}_{2} 1.5 \mathrm{mM}, \mathrm{NaCl}\right.$ $118 \mathrm{mM}, \mathrm{KCl} 4.7 \mathrm{mM}, \mathrm{MgSO}_{4} 1.1 \mathrm{mM}, \mathrm{KH}_{2} \mathrm{PO}_{4} 1.2 \mathrm{mM}$, $\mathrm{NaHCO}_{3} 25 \mathrm{mM}$, and glucose $10 \mathrm{mM}$; pH 7.4). The ciliary muscle was carefully ablated from the sclera after removal of the crystalline lens, cut into a $3 \mathrm{~mm} \times 6 \mathrm{~mm}$ strip, and suspended in Krebs solution bubbled with a gas mixture of $5 \% \quad \mathrm{CO}_{2}$ and $95 \% \quad \mathrm{O}_{2}$ at $37^{\circ} \mathrm{C}$. Muscle contractions were measured using force transducers connected to a physiograph recorder (Powerlab 4/30; AD Instruments, New South Wales, Australia) and a Power Lab data-acquisition system. Basal tension was applied at a loading weight of $1 \mathrm{~g}$ using a tension transducer. Following 90 min of equilibration, the ciliary muscle was stimulated by the addition of $100 \mu \mathrm{M} / \mathrm{mL}$ carbachol. When the resultant tension reached a plateau value, the ciliary muscle was washed with Krebs solution. After 30 min, upon establishment of baseline tension, a second stimulation was applied by a further addition of 100 $\mu \mathrm{M} / \mathrm{mL}$ carbachol. This process was repeated multiple times, and each time, the ciliary muscle was washed with Krebs solution to re-establish the baseline. After the tenth stimulation, PFA (100 and $200 \mu \mathrm{g} / \mathrm{mL}$ ) was added to the ciliary muscle, and the resultant tension was monitored. 
This study was performed according to the guidelines of the Animal Care and use review Committee of Jeollanamdo Institute of Natural Resources Research (JINR 1603).

\subsection{Mechanisms Underlying Smooth Muscle Relaxation}

\subsubsection{Measurement of cGMP and cAMP Production}

Primary human aortic smooth muscle cells (hASMCs) were purchased from the ATCC (American Type Culture Collection, PCS-100-012, Manassas, VA, USA) and maintained in vascular cell basal medium (ATCC, PCS-100-030) supplemented with vascular smooth muscle cell growth kit (ATCC, PCS-100-042) in a humidified cell incubator under an atmosphere of $5 \% \mathrm{CO}_{2}$ at $37^{\circ} \mathrm{C}$. For experiments, hASMCs were plated in complete medium on 6 -well plates at a concentration of $5 \times 10^{5}$ cells/well. After $24 \mathrm{~h}$, cells were pretreated for $10 \mathrm{~min}$ with PBS buffer containing $1 \mathrm{mM}$ 3-isobutyl-1-methylxanthine (IBMX), a phosphodiesterase inhibitor. PFA (50, 100, and $200 \mu \mathrm{g} / \mathrm{mL}$ ) was then added and the cells were incubated for 15, 30, and $60 \mathrm{~min}$. Media was aspirated and the cGMP content of each sample was determined using a cyclic GMP ELISA kit from Cell Biolabs, Inc. (San Diego, CA), according to the manufacturer's instructions. Intracellular cAMP levels were measured using a cAMP Parameter ${ }^{\mathrm{TM}}$ assay kit (R\&D Systems Europe, Ltd., Abingdon, UK) according to the manufacturer's instructions.

\subsubsection{Phosphodiesterase (PDE) Inhibitory Activity of PFA}

PDE5A and PDE3A activities were assayed using kits according to the manufacturer's instructions (BPS Bioscience, San Diego, CA). Briefly, each $50 \mu \mathrm{L}$ reaction mixture contained $10 \mathrm{ng} / \mathrm{mL}$ PDE5A or $20 \mathrm{ng} / \mathrm{mL}$ PDE3A, or both, and $200 \mathrm{nM}$ FAM-Cyclic-3',5'-GMP or $200 \mathrm{nM}$ FAM-Cyclic-3',5'-AMP, or both. PFA (50, 100, and 200 $\mu \mathrm{g} / \mathrm{mL}$ ) was diluted in PDE assay buffer, and $5 \mu \mathrm{L}$ of the dilution was added to a $50 \mu \mathrm{L}$ reaction volume. The reaction mixtures were incubated at room temperature for $1 \mathrm{~h}$. A diluted binding agent $(100 \mu \mathrm{L})$ was then added to each well, and the reaction mixtures were incubated at room temperature for $1 \mathrm{~h}$ with slow shaking. The fluorescence polarization of each sample was obtained using a $480 \mathrm{~nm}$ excitation filter and $528 \mathrm{~nm}$ emission filter. The percentage of inhibition was calculated using the following formula (1).

$$
\begin{aligned}
& \% \text { activity } \\
& =\left[\left(\mathrm{F}_{\text {drug }}-\mathrm{F}_{\text {control }}\right) /\left(\mathrm{F}_{\text {enzyme }}-\mathrm{F}_{\text {control }}\right)\right] \times 100 \text {. }
\end{aligned}
$$

\subsubsection{Measurement of $\left[\mathrm{Ca}^{2+}\right] i$}

The $\left[\mathrm{Ca}^{2+}\right] i$ levels inhibition in muscle cells of PFA was measured using the method reported by Lee et al [32]. The acetoxymethyl-ester form of Fura-2 (Fura-2/AM) was used as the fluorescent $\mathrm{Ca}^{2+}$ indicator. hASMCs were incubated for $60 \mathrm{~min}$ at room temperature with $5 \mu \mathrm{M}$ Fura-2/AM and $0.001 \%$ Pluronic F-127 in HEPES-buffered solution of the following composition (in $\mathrm{mM}$ ): $155 \mathrm{NaCl}, 3 \mathrm{KCl}$,
$2 \mathrm{CaCl}_{2}, 10 \mathrm{HEPES}, 10$ glucose, and $1 \mu \mathrm{M}$ glycine, adjusted to $\mathrm{pH} 7.4$ with $\mathrm{NaOH}$. The cells were stabilized in HEPES-buffered solution for $5 \mathrm{~min}$, followed by PFA treatment $(50,100$, and $200 \mu \mathrm{g} / \mathrm{mL})$ for $100 \mathrm{~s}$ to confirm changes in $\left[\mathrm{Ca}^{2+}\right] i$ levels. To induce a $\left[\mathrm{Ca}^{2+}\right]$ response, the cells were stimulated with endothelin-1 (ET-1; $10 \mathrm{nM})$ for $100 \mathrm{~s}$ following treatment with PFA (50, 100, and 200 $\mu \mathrm{g} / \mathrm{mL}$ ) or control for $100 \mathrm{~s}$. Next, the cells were illuminated using Lambda XL and excitation wavelengths of 340 and $380 \mathrm{~nm}$ were selected. Data were acquired every 2 s. All imaging data were collected and analyzed using MetaMorph software.

\subsection{Clinical Measurement of Accommodation}

\subsubsection{Study Design}

This study was approved by the Institutional Review Board (IRB) of Dongshin University Oriental Hospital (IRB approval number: DSGOH-033). The study design was a randomized, placebo-controlled, double-blind comparison study. Thirty participants who have no eye disease were randomly assigned to the test and placebo groups $(n=30$ per group). Each subject intake test sample and placebo during 1 week, and VDT loads were imposed by having the subjects play smartphone for $2 \mathrm{~h}$ on the final days.

\subsubsection{Near Point of Accommodation (NPA)}

NPA (in $\mathrm{cm}$ ) was evaluated before and after $2 \mathrm{~h}$ of VDT work in the test sample and placebo group after using push-up tests. A 20/30 single letter on a fixation stick, positioned approximately $40 \mathrm{~cm}$ from the subject, served as the target and was moved gradually closer to the subject until the subject noticed the target starting to blur. This was considered the endpoint.

\subsection{Statistical Analysis}

The results of in vitro and ex vivo tests are expressed as the mean \pm standard error of the mean (SEM). Data from the groups were compared by analysis of variance (ANOVA), followed by Dunnet's post hoc test. All statistical analyses were performed using GraphPad Prism 5 for Windows (GraphPad Software, San Diego, California, USA). Clinical test data were expressed as the mean \pm SE. Analysis between the groups was performed via $t$-test using SPSS 21.0. $P$ values $<0.05$ were considered statistically significant.

\section{Results}

\subsection{Effect of PFA on Antioxidant Activity}

Quantitative HPLC analysis of PFA revealed three main antioxidant compounds: rosmarinic acid, luteolin-7$\mathrm{O}$-glucuronide, and apigenin-7-O-glucuronide (Figure 1 ). We investigated the inhibitory effect of PFA on $\mathrm{H}_{2} \mathrm{O}_{2}$ induced oxidative stress in muscle cells and observed that PFA inhibited ROS generation in $\mathrm{H}_{2} \mathrm{O}_{2}$-induced $\mathrm{C} 2 \mathrm{C} 12$ cells in a dose-dependent manner (Figure 2B), without causing cell toxicity (Figure 2A). 


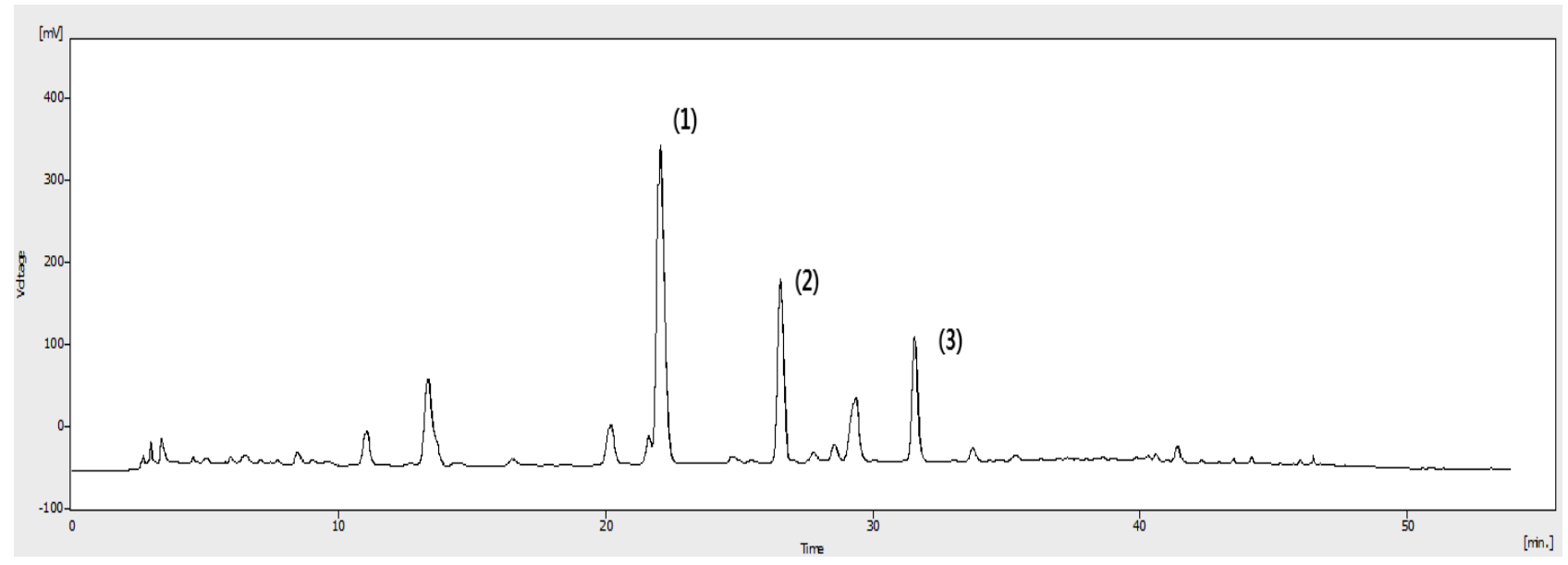

Figure 1. HPLC chromatogram of Perilla frutescens var. acuta aqueous extracts (PFA). (1) Luteolin-7-O- $\beta$-D-diglucuronide, (2) Apigenin -7-O- $\beta$-Ddiglucuronide, (3) Rosmarinic acid

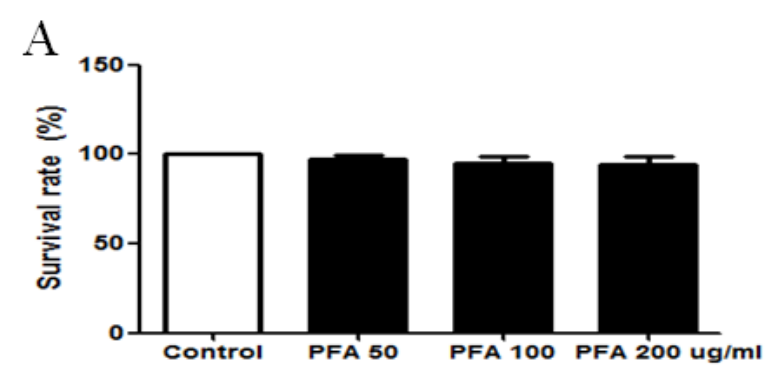

$\mathrm{B}$

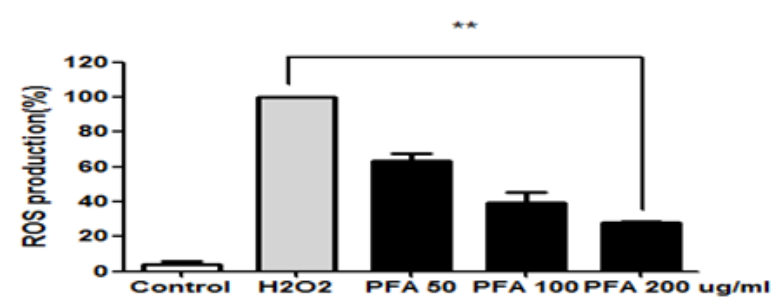

Figure 2. Effect of PFA on cell viability (A) and ROS production (B) in $\mathrm{H}_{2} \mathrm{O}_{2}$-induced C2C12 cells. Cells were pretreated with PFA (50, 100, and $200 \mu \mathrm{g} / \mathrm{mL}$ ) for $24 \mathrm{~h}$ prior to treatment with $\mathrm{H}_{2} \mathrm{O}_{2}(200 \mu \mathrm{M})$ for $2 \mathrm{~h}$. Cells were then stained with $10 \mu \mathrm{M}$ DCFH-DA and fluorescence was measured at excitation and emission wavelengths of 485 and $530 \mathrm{~nm}$, respectively. Data are presented as mean \pm SEM of three experiments. * $P<0.05$ and ${ }^{* *} P<0.01$ compared with $\mathrm{H}_{2} \mathrm{O}_{2}$-treated cells

\subsection{Effect of PFA on Ciliary Muscle Relaxation}

We evaluated the ability of PFA to cause relaxation in rabbit ciliary muscle. After the resting tension of each ciliary muscle strip had stabilized, sustained contraction of approximately $100 \mathrm{mg}$ was maintained by the addition of $100 \mu \mathrm{M} / \mathrm{mL}$ carbachol (Figure 3). After stabilization of carbachol-induced contraction, PFA was added, resulting in sustained and progressive relaxation within 40-60 min. The control (distilled water) exerted no relaxation effect on carbachol-induced contraction, while PFA $(200 \mu \mathrm{g} / \mathrm{mL})$ produced significant relaxation.

\subsection{Effect of PFA on Cyclic GMP and Cyclic AMP Levels}

We investigated whether PFA increased intracellular
cGMP and cAMP production in hASMCs. PFA (50, 100, and $200 \mu \mathrm{g} / \mathrm{mL}$ ) produced a concentration- and timedependent increase in intracellular cGMP levels, with stimulation observed 15-60 min after the addition of the extract (Figure 4A). In addition, PFA had no apparent effect on cAMP levels at different concentrations and incubation times (Figure 4B). These results showed that PFA directly increased cGMP concentrations $(P<0.05$ and $P<0.01$ ), but no significant effect on cAMP levels was observed $(P>0.05)$.

\subsection{Effect of PFA on PDE inhibitory Activity}

We examined the effect of PFA on PDE5A and PDE3A inhibitory activity using the PDE assay kit. PFA significantly inhibited PDE5A activity in a dosedependent manner, but no inhibitory effect was observed on PDE3A activity (Figure 5A, B). PFA treatment at concentrations of 50,100 , and $200 \mu \mathrm{g} / \mathrm{mL}$ inhibited PDE5A activity in a dose-dependent manner to $51.23 \pm$ $0.29,42.42 \pm 0.13$, and $36.58 \pm 0.37 \%$, respectively (Figure 5A).

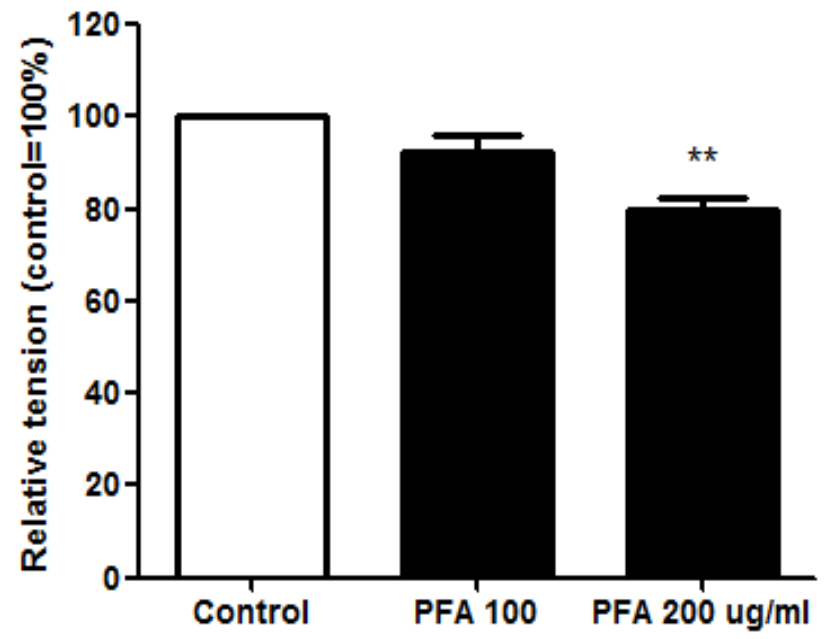

Figure 3. Relaxation effects of PFA on carbachol-induced contraction in rabbit ciliary muscles. Ciliary muscles were stimulated with carbachol (100 $\mu \mathrm{M})$ and then treated with PFA (100 and $200 \mu \mathrm{g} / \mathrm{mL})$. The relaxation rate of PFA is expressed as the percentage of the respective component control. Data are expressed as mean \pm SEM of three experiments. ${ }^{*} P<0.05$ and ${ }^{* *} P<0.01$ compared with control (CT) 
A

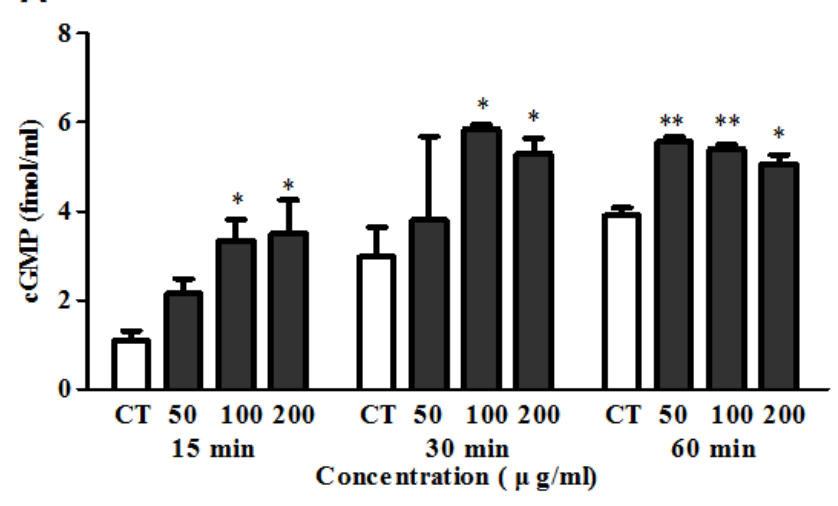

B

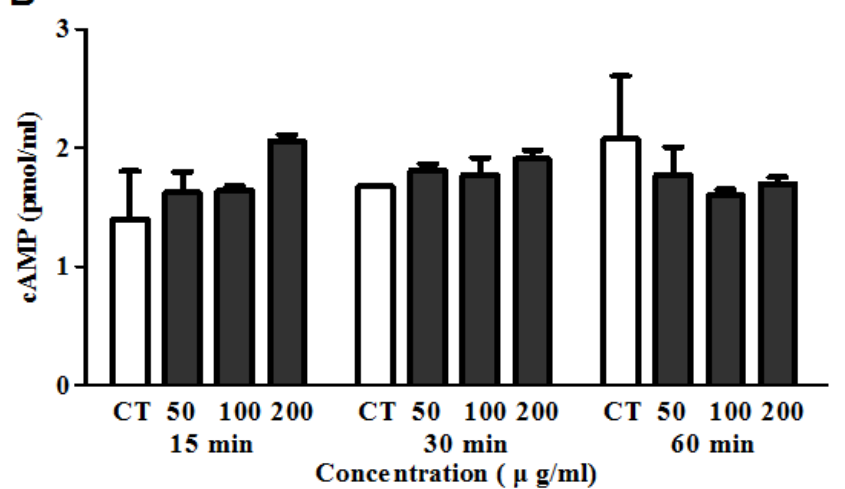

Figure 4. Effect of PFA on cGMP and cAMP levels in hASMCs. (A) Intracellular concentration of cGMP after 15, 30, and 60 min of PFA treatment at 50, 100, and $200 \mu \mathrm{g} / \mathrm{mL}$. (B) Intracellular concentration of cAMP after 15, 30, and $60 \mathrm{~min}$ of PFA treatment at 50, 100, and $200 \mu \mathrm{g} / \mathrm{mL}$. The values are expressed as mean \pm SEM of three experiments. $* P<0.05$ and ${ }^{* *} P<0.01$ compared with control (CT)
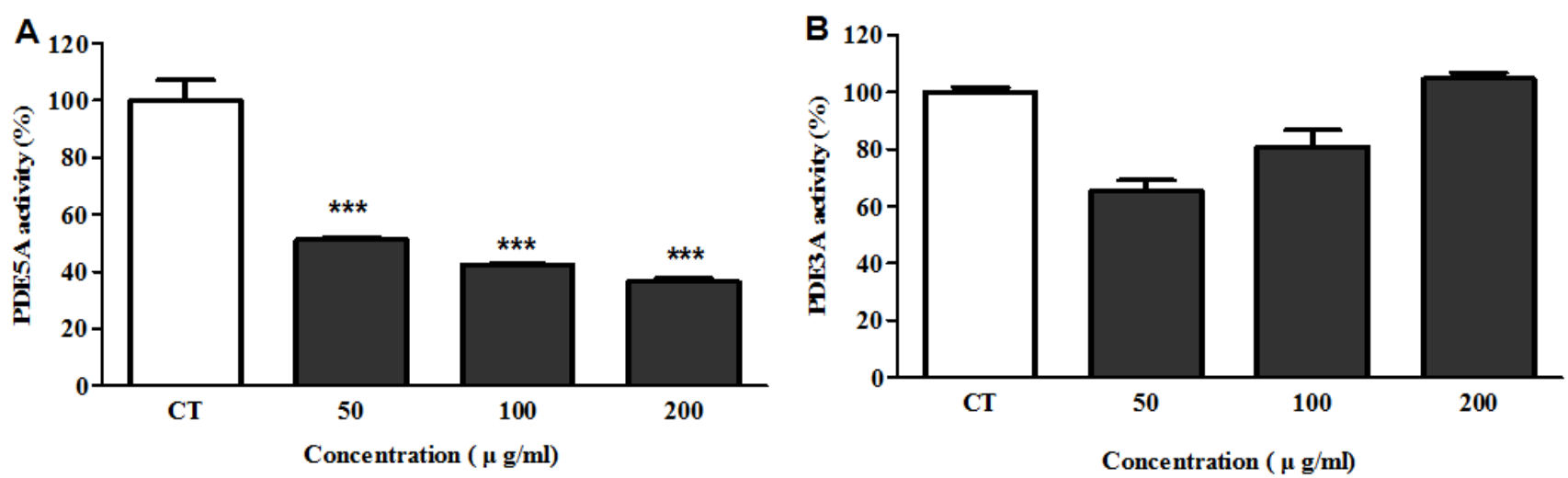

Figure 5. Effect of PFA on PDE activity. Effect of PFA on isoenzyme-specific cGMP-PDE activity for PDE5A (A) and cAMP-PDE activity for PDE3A (B) was measured. The values are expressed as the mean \pm SEM of three experiments. ${ }^{* * *} P<0.001$ compared with control (CT)

A

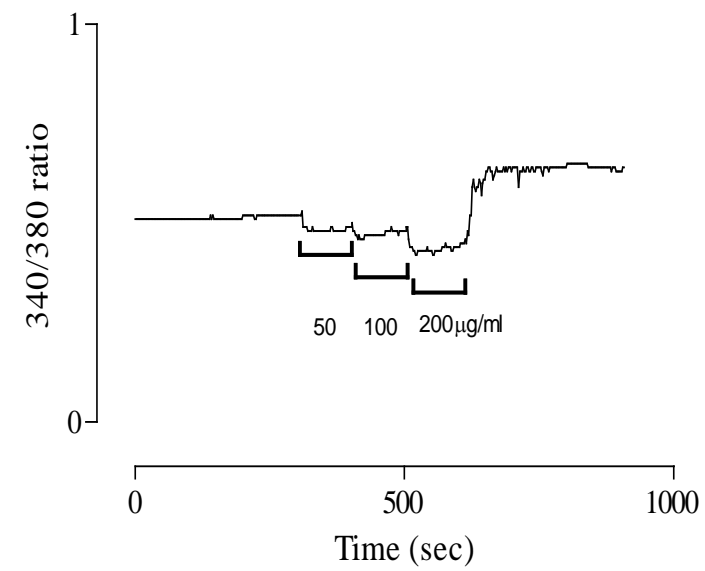

B
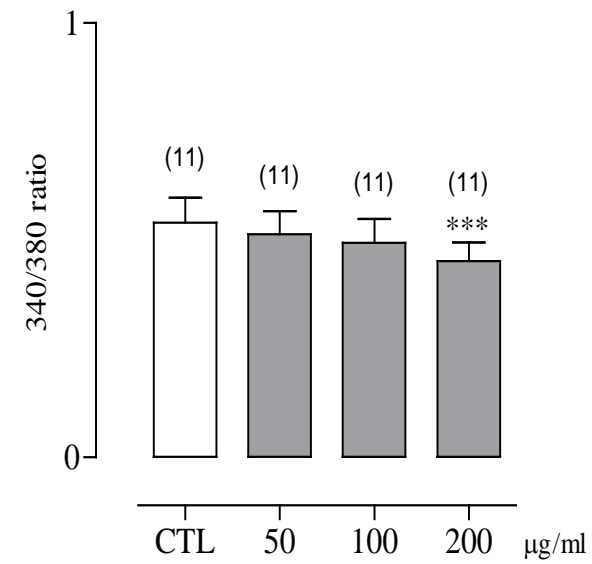

Figure 6. Effects of PFA on basal $\left[\mathrm{Ca}^{2+}\right]_{\mathrm{i}}$ of hASMCs. (a) Representative tracing of the $\left[\mathrm{Ca}^{2+}\right]_{\mathrm{i}}$ response evoked by various concentrations of PFA (50, 100 , and $200 \mu \mathrm{g} / \mathrm{mL}$ ) (b) The panel shows the summarized data of PFA-induced changes in $\left[\mathrm{Ca}^{2+}\right]_{\mathrm{i}}$ in hASMCs. The results are expressed as mean \pm SEM of basal $\left[\mathrm{Ca}^{2+}\right]_{\mathrm{i}}$, in PFA-treated hASMCs. $\mathrm{n}=11$, ***P $<0.001$ compared with control (CT)

\subsection{Effect of PFA on Basal $\left[\mathrm{Ca}^{2+}\right]_{i}$ in Muscle Cells}

To investigate whether the inhibitory effect of PFA on muscular contraction is associated with the attenuation of $\left[\mathrm{Ca}^{2+}\right]_{i}$, we examined its effects on $\left[\mathrm{Ca}^{2+}\right]_{i}$ levels using Fura-2 ratiometric $\mathrm{Ca}^{2+}$ imaging. As shown in Figure 6, the control had no effect on $\left[\mathrm{Ca}^{2+}\right]_{i}$. However, PFA significantly reduced basal $\left[\mathrm{Ca}^{2+}\right]_{i}$ levels in a dosedependent manner.

\subsection{Inhibition of ET-1-induced $\left[\mathrm{Ca}^{2+}\right]_{i}$ Increase by PFA in Muscle Cells}

To confirm the effects of PFA on $\mathrm{Ca}^{2+}$ signaling in smooth muscle cells, we determined whether $\mathrm{Ca}^{2+}$ release 
was affected by PFA. Application of $10 \mathrm{nM}$ of ET-1 $(P<0.001)$ in $\left[\mathrm{Ca}^{2+}\right]_{i}$, which was inhibited by PFA to hASMCs induced a statistically significant elevation treatment (50, 100, and $200 \mu \mathrm{g} / \mathrm{mL}$; Figure 7).
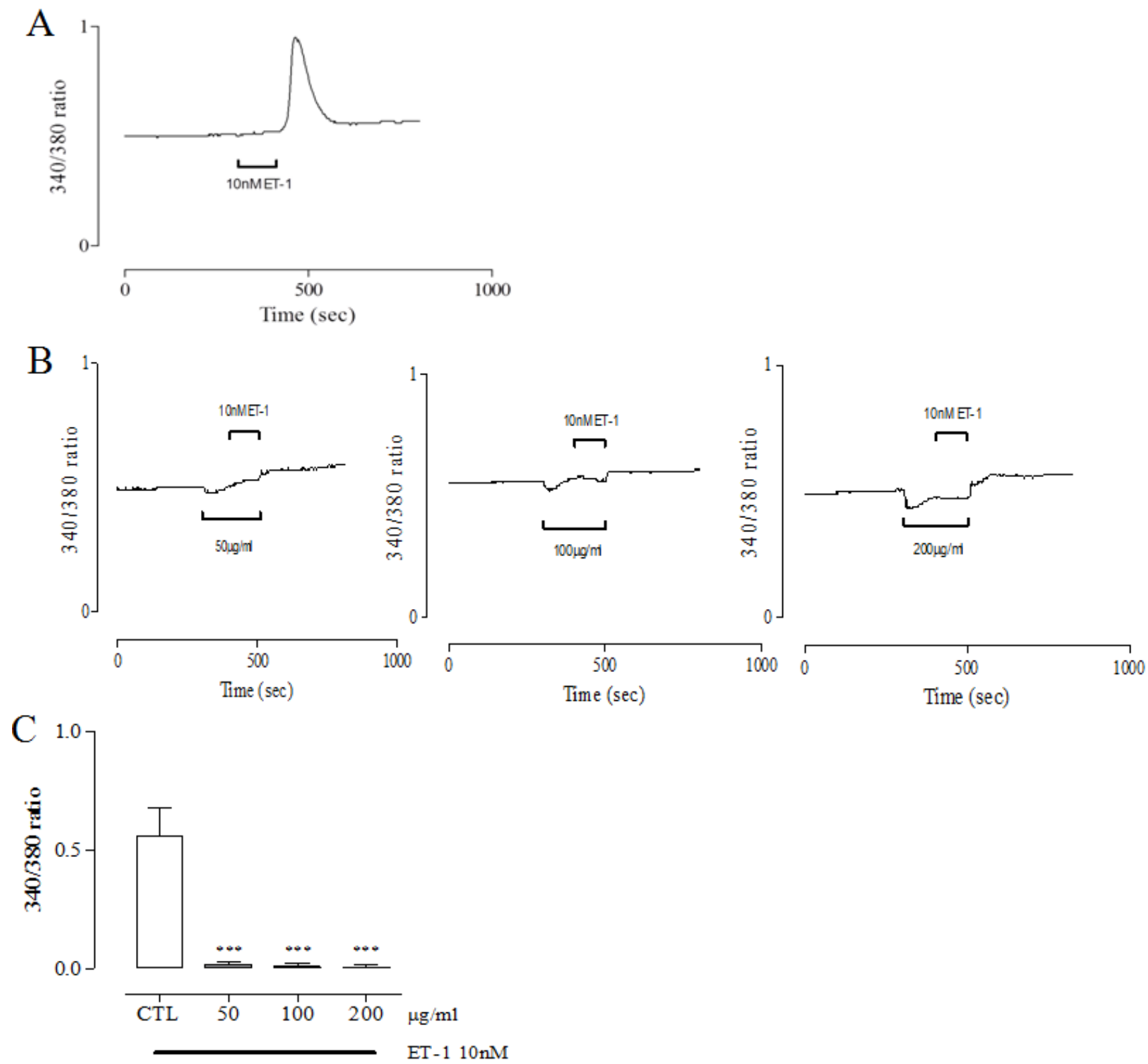

Figure 7. Inhibitory effects of PFA treatment on ET-1 (10 nM)-induced $\left[\mathrm{Ca}^{2+}\right]_{\mathrm{i}}$ response in hASMCs. (a) $\left[\mathrm{Ca}^{2+}\right]_{\mathrm{i}}$ responses induced by ET-1 (10 nM, $100 \mathrm{~s})$. (b) Inhibitory effects of PFA pretreatment $(50,100$, and $200 \mu \mathrm{g} / \mathrm{mL}$ for $100 \mathrm{~s})$ on ET-1-induced $\left[\mathrm{Ca}^{2+}\right]_{\mathrm{I}}$ responses (c) The panel shows the summary of the mean $\pm \mathrm{SEM}$ of $\left[\mathrm{Ca}^{2+}\right]_{\text {. }}$. Inhibition of ET-1-induced $\left[\mathrm{Ca}^{2+}\right]_{i}$ responses by PFA. $\mathrm{n}=(11),{ }^{* * *} \mathrm{P}<0.001$ compared with control $(\mathrm{CT})$, ET-1 = endothelin-1

Table 1. Change of NPA values before and after VDT work for $2 \mathrm{~h}$ of PFA and Placebo

\begin{tabular}{|c|c|c|c|c|c|c|}
\hline $\mathrm{NPA}^{1}(\mathrm{~cm})$ & & Before & After & Change & t-test & $\mathrm{p}$-value \\
\hline \multirow[t]{3}{*}{$\mathrm{PFA}^{2}$} & Dominant eye & $8.68 \pm 2.98$ & $7.83 \pm 3.08$ & $-0.85 \pm 1.32$ & $t=-3.53$ & $P<0.001$ \\
\hline & Non-dominant eye & $8.38 \pm 3.13$ & $7.67 \pm 3.21$ & $-0.71 \pm 1.21$ & $\mathrm{t}=-3.20$ & $P<0.001$ \\
\hline & Both eye & $7.96 \pm 2.97$ & $7.27 \pm 3.25$ & $-0.69 \pm 1.46$ & $t=-2.60$ & $P<0.001$ \\
\hline \multirow[t]{3}{*}{ Placebo } & Dominant eye & $8.90 \pm 2.60$ & $9.63 \pm 2.40$ & $+0.73 \pm 0.79$ & $t=5.12$ & $P<0.001$ \\
\hline & Non-dominant eye & $8.60 \pm 2.49$ & $9.43 \pm 2.42$ & $+0.83 \pm 1.12$ & $\mathrm{t}=4.09$ & $P<0.001$ \\
\hline & Both eye & $9.00 \pm 2.45$ & $9.67 \pm 2.48$ & $+0.67 \pm 0.84$ & $t=4.33$ & $P<0.001$ \\
\hline
\end{tabular}

Unit: $\mathrm{cm}, \mathrm{p}<0.05$

All values are expressed as the mean $\pm \mathrm{SE}$.

${ }^{1}$ NPA Near point accommodation, ${ }^{2}$ PFA: Perilla frutescens var. acuta aqueous extracts. 


\subsection{Effect of PFA on VDT-induced Ocular Fatigue Assessed by NPA}

NPA was measured before and after VDT work for $2 \mathrm{~h}$, and was $8.68 \pm 2.98$ and $7.83 \pm 3.08 \mathrm{~cm}$, respectively, in the dominant eye, indicating a significant decrease $(P<0.001)$. The NPA for the non-dominant eye was $8.38 \pm 3.13 \mathrm{~cm}$ before VDT use and $7.67 \pm 3.21 \mathrm{~cm}$ after $2 \mathrm{~h}$ of VDT use, also indicating a significant decrease $(P<0.001)$. The NPA for both the eyes before and after $2 \mathrm{~h}$ of VDT work was $7.96 \pm 2.97$ and $7.27 \pm 3.25 \mathrm{~cm}$, respectively, representing a significant decrease $(P<0.001)$. However, NPA did not improve in the placebo group. The NPA in the placebo group before and after $2 \mathrm{~h}$ of VDT use was $8.90 \pm 2.60$ and $9.63 \pm 2.40 \mathrm{~cm}$, respectively, for the dominant eye $(P<$ 0.001). For the non-dominant eye, the NPA before and after $2 \mathrm{~h}$ of VDT work was $8.60 \pm 2.49$ and $9.43 \pm 2.42 \mathrm{~cm}$, respectively $(P<0.001)$. The NPA for both eyes before and after $2 \mathrm{~h}$ of VDT work was $9.00 \pm 2.45$ and $9.67 \pm 2.48$ cm, respectively $(P<0.001$; Table 1$)$.

\section{Discussion}

Recently, the widespread use of various VDTs, such as smartphones, televisions, and computer monitors, has become a serious global health concern [33,34]. Increased VDT use has resulted in a concurrent increase in various symptoms associated with eye fatigue, including ocular pain, dry eye sensation, excess tears, and blurred vision $[4,5]$. The aim of the present study was to investigate whether PFA exerts ameliorating effects on visual fatigue. Several studies have demonstrated that certain food ingredients, such as docosahexaenoic acid [35], eicosapentaenoic acid [35], omega-3 fatty acids [36], lutein [37], zeaxanthin [37], astaxanthin [9], bilberry extract [2], black soybean hull extract [9], and anthocyanin [19,38] can improve visual fatigue.

Some studies have examined the relationship between oxidative stress and various ophthalmic diseases [8,39]. Food constituents with antioxidants have been reported to be effective in improving visual systems [13]. Other studies have reported that astaxanthin, bilberry extract, and lutein exert antioxidant effects [2,9]. In support of these reports, we identified the major polyphenolic components in PFA as apigenin-7-O-diglucuronide, luteolin-7-O-diglucuronide, and rosmarinic acid using HPLC analysis, and these compounds showed antioxidant activity. In addition, our experimental results showed that PFA significantly inhibited ROS generation in $\mathrm{H}_{2} \mathrm{O}_{2}$-induced muscle cells without causing cell toxicity.

The accommodative ability of the eyes, controlled by the action of ciliary muscle, may directly lead to eye fatigue [40]. In a previous study, it was reported that astaxanthin may improve accommodation owing to its relaxing effect on the ciliary muscle [41,42]. Moreover, bilberry and black soybean hull extracts improved accommodative ability and ciliary muscle relaxant effects [9]. We conducted a randomized, placebo-controlled, double-blind comparison study of 30 subjects to verify the effect of PFA on the accommodative ability of the eye. By measuring NPA, we showed that VDT work for $2 \mathrm{~h}$ significantly improved accommodative ability compared with placebo. Increased cGMP content in smooth muscle cells suppresses contractions. In this study, PFA (200 $\mu \mathrm{g} / \mathrm{mL}$ ) relaxed carbachol-induced contractions of ciliary muscles. In accordance with the results of previous studies, our data indicate that PFA induced the relaxation of carbachol-induced ciliary muscle contraction via increased cGMP production. However, PFA did not affect cAMP content. PDEs selectively degrade both cAMP and cGMP through hydrolysis in smooth muscle tissues [43]. cAMP hydrolysis is mediated by PDE1, 2, 3, and 10 and cGMP hydrolysis by PDE5, 6, and 9 [43]. In this study, we demonstrated that PFA significantly inhibited PDE5A activity in a dose-dependent manner, but exhibited no inhibitory effect on PDE3A activity. In a previous study, delphinidin-3-rutinoside relaxed bovine ciliary smooth muscle by activating the ET-B receptor and the NO/cGMP pathway [20]. In addition, it has been reported that bovine ciliary smooth muscle relaxation is mediated by the cGMP pathway [44]. Furthermore, cGMP is known to decrease $\mathrm{Ca}^{2+}$ levels in smooth muscle cells, thus leading to smooth muscle relaxation [20]. Our results indicate that PFA treatment $(50,100$, and $200 \mu \mathrm{g} / \mathrm{mL})$ significantly reduced basal $\left[\mathrm{Ca}^{2+}\right]_{i}$ and inhibited ET-1-induced $\left[\mathrm{Ca}^{2+}\right]_{i}$ in a dosedependent manner.

\section{Conclusion}

In conclusion, this is the first study to demonstrate that PFA ameliorated visual fatigue. PFA also mediated the relaxation of ciliary smooth muscle via the cGMP pathway, and significantly improved accommodative ability compared with the placebo group in a clinical study. Our results indicate the beneficial effects of PFA in improving visual fatigue.

\section{Acknowledgements}

This research was supported by the Support Program for Creative Industry Institutes (Commercial Biotechnology Sophistication Platform Construction Program, R0003950) funded by the Ministry of Trade, Industry \& Energy (MOTIE, Korea).

\section{Conflicts of Interest}

The authors have no conflicts of interest to declare.

\section{List of Abbreviations}

NPA, near point of accommodation; PFA, Perilla frutescens var. acuta aqueous extract; ROS, reactive oxygen species; PDE, phosphodiesterase.

\section{References}

[1] Parihar, JK., Jain, VK., Chaturvedi, P., Kaushik, J., Jain, G. and Parihar, KS, "Computer and visual display terminals (VDT) visionsyndrome (CVDTS)," Medical Journal Armed for India, 72(3), 270-276, 2016. 
[2] Ozawa, Y., Kawashia, M., Inoue, S., Inacgki, E., Suzuki, A., Ooe, E., Kobayashi, S. and Tsubota, K, "Bilberry extract supplementation for preventing eye fatigue in video disply terminal workers," The Journal of Nutrition Health \& Aging, 19(5), 548-554, 2015.

[3] Yoshihara, A., Yamanaka, K. and Kawakami, M, "Effects of polyphenol on visual fatigue caused by VDT work," International Journal of Occupational Safety and Ergonomics, 15(3), 339-343, 2009.

[4] Goto, E., Yagi, Y., Matsumoto, Y. and Tsubota, K, "Imparied functional visual acuity of dry eye patients," American Journal of ophthalmology, 133(2), 181-186, 2002.

[5] Wolkoff, P., Nojgaaard, JK., Troiano, P. and Piccoli, B, "Eye complaints in the office environment: precorneal tar film integrity in fluenced by eye blinking efficiency," Occupational and enviromental medicine, 62(1), 4-12, 2005.

[6] Loh, KY. and Reddy, SC, "Understanding and preventing computer vision syndrome," Malaysian Family Physician, 3(3), 128-130, 2008

[7] Hashimoto, H., Arai, K., Hayashi, S., Okamoto, H., Takahashi, J., Chikuda, M. and Obara, Y, "Effects of astaxanthin on antioxidation in human aqueous humor," Journal of Clinical Biochemistry and Nutrition, 53(1), 1-7, 2013.

[8] Michael, R. and Bron, AJ, "The ageing lens and cataract: a model of normal and pathological ageing," Philosophical Transactions of The Royal Society B, 366(1568), 1278-1292, 2011.

[9] Kona, K., Shimizu, Y., Takahashi, S. and Yui, K, "Effect of multiple dietary supplement containing lutein, astaxanthin, cyaniding-3-glucoside,and DHA on accommodative ability," Immunology, Endocrine and Metabolic Agent in Medicinal Chemistry, 14(2), 114-125, 2014.

[10] Park, CY., Gu, N., Lim, CY., Oh, JH., Chang, M., Kim, M. and Rhee, MY, "The effect of Vaccinium uliginosum extract on tablet computer induced asthenopia: randomized placebo-controlled study," BMC Complementary and Alternative Medicine, 1-9, 2016.1

[11] Ozawa, Y., Kawashima, M., Inoue, S., Inagaki, E., Suzuki, A., Ooe, E., Kobayashi, S. and Tsubota, K, "Bilberry extract supplementation for preventing eye fatigue in video display terminal workers," The journal of Nutrition, Health \& Aging, 19(5), 548-554, 2015.

[12] Wee, SW. and Moon, NJ, "Clinical evaluation of accommodation and ocular surface stability relavant to visual asthenopia with 3D displays," BMC Opthalmology, 14(29), 1-6, 2014.

[13] Uchino, Y., Uchino, M., Dogru, M., Fukagawa, K. and Tsubota, K, "Improvement of accommodation with anti-oxidant supplementation in visual display terminal users," The journal of nutrition, health \& aging, 16(5), 478-481, 2012.

[14] Iwao, K. and Tsutomu, A, "A novel in vitro model for screening and evaluation of anti-asthenopia drug," Journal of Pharmacological Sciences, 93, 222-224, 2003.

[15] Richdale, K., Sinnott, L., Bullimore, MA., Wassenaar, PA., Schmalbrock, P., Kao, CY., Patz, S., Mutti, DO., Glasser, A. and Zadnik, K, "Quantification of age-related and per diopter accommodative changes of the lens and ciliary muscle in the emmetropic human eye," Investigative Ophthalmology \& Visual Science, 54(2), 1095-1105, 2013.

[16] Park, KA., Yun, JH. and Kee, CW, "The effect of cataract extraction on the contractility of ciliary muscle," American Journal of Ophthalmology,146(1), 8-14, 2008.

[17] Hermans, EA., Dubbelman, M., Heijde, V. and Heethaar, RM, "Estimating the external force acting on the human eye lens during accommodation by finite element modeling," Vision Research, 46(21), 3642-3650, 2006.

[18] Beauregard, C., Liu, Q. and Chiou, GC, "Effects of nitric oxide donors and nitric oxide synthase substrates on ciliary muscle contracted by carbachol and endothelin for possible use in myopia prevention," Journal of Ocular Pharmacology and Therapeutics, 17(1), 1-9, 2001.

[19] Matsumoto, H., Kamm, KE., Stull, JT. and Azuma, H, "Delphinidin-3-rutinoside relaxes the bovine ciliary smooth muscle through activation of ETB receptor and NO/cGMP pathway," Experimental Eye Research, 80(3), 313-322, 2005.

[20] Noriko, W., Yukari, T., Kazuya, M., Takahiro, O., Hiroma, TU. and Yasuo, G, "Inhibitory effects of amlexanox on carbachol-induced contractions of rabbit ciliary muscle and guinea-pig taenia caecum," Journal of Pharmacy and Pharmacology, 52(11), 1377 1385, 2000.

[21] Lee, CW., Choi, HM., Kim, SY., Lee, JR., Kim, HJ., JO, C. and Jung, S, "Influence of Perilla frutescens var. acuta water extract on the shelf life and physicochemical qualities of cooked beef patties," Korean Journal of Food Science of Animal Resources, 35(3), 389-397, 2015.

[22] Kim, EY., Choi, HJ., Chung, TW., Choi, JY., Kim, HS., Jung, YS. Lee, SO. and $\mathrm{Ha}, \mathrm{KT}$, "Water-extracted Perilla frutescens increases endometrial receptivity though leukemia inhibitory factor-dependent expression of integrins," Journal of Pharmacological Scienses, 131(4), 259-266, 2016.

[23] Fengxian, Z., Takayuki, A., Akihiko, S., Yoriko, K., Hisashi, N. and Hirotoshi, T, "Rosmarinic acid extract for antioxidant, antiallergic, and $\alpha$-glucosidase inhibitory activities, isolated by supramolecular technique and solvent extraction from Perilla leaves," Journal of Agriculaura and Food Chemistry, 62(4), 885892, 2014.

[24] Jun, HI., Kim, BT., Song, GS. and Kim, YS, "Structural characterization of phenolic antioxidants from purple perilla (Perilla frutescens var. acuta) leaves," Food Chemistry, 148(1), 367-372, 2014.

[25] Meng, L., Loazno, YF., Gaydou, EM. and Li, B, "Antioxidant activities of polyphenols extracted from Perilla frutescens varieties," Molecules, 14(1), 133-140, 2009.

[26] Banno, N., Akihisa, T., Tokuda, H., Yasukawa, K., Hicashihara, H., Ukiya, M., Watanabe, K., Kimura, Y., Hasegawa, J. and Nishino, H, "Triterpene acids from the leaves of Perilla frutescens and their anti-inflammatory and antitumor-promoting effects," Bioscience Biotechnology, and Biochemistry, 68(1), 85-90, 2004.

[27] Oh, HA., Park, CS., Ahn, HJ., Park, YS. and Kim, HM, "Effect of Perilla frutescens var. acuta Kudo and rosmarinic acid on allergic inflammatory reactions," Experimental Biology and Medicine, 236(1), 99-106, 2011.

[28] Kang, R., Helms, R., Stout, MJ., Jaber, H., Chen, Z. and Nakatsu, T, "Antimicrobial activitiy of the volatile constituents of Perilla frutescens and its sysnergistic effects with polygodial," Journal of Agricultural and Food Chemistry, 40(11), 2326-2330, 1992.

[29] Meng, L., Lozano, Y., Bombarda, I., Gaydou, EM. and Li, B, "Polyphenol extraction from eight Perilla frutescens cultivars," Comptes Rendus Chimie, 12(5), 602-611, 2009.

[30] Kim, EY., Choi, HJ., Chung, TW., Choi, JY., Kim, HS., Jung, YS., Lee, SO. and Ha, KT, "Water-extracted Perilla frutescens increases endometrial receptivity though leukemia inhibitory factor-dependent expression of integrins," Journal of Pharmacological Sciences, 131(4), 259-266, 2016

[31] Kim, SH., Hwang, JT., Park, HS., Kwon, DY. and Kim, MS, "Capsaicin stimulates glucose uptake in $\mathrm{C} 2 \mathrm{Cl} 2$ muscle cells via the reactive oxygen species (ROS)/AMPK/p38 MAPK pathway," Biochemical and Biophysical Research Communications, 439(1), 66-70, 2013.

[32] Lee, JH., Chae, MR., Sung, HH., Ko, M., Kang, SJ. and Lee, SW, "Endothelium-independent relaxant effect of Rubus Coreanus extracts in corpus cavernosum smooth muscle," International Society for Sexual Medicine, 10(7), 1720-1729, 2013.

[33] Davey, S. and Davey, A, "Assessment of smartphone addiction in Indian adolescents: a mixed method study by systematic-review and meta-analysis approach," International Journal of Preventive Medicine, 5(12), 1500-1511, 2014

[34] Nathan, N. and Zeitzer, J, "A survey study of the association between mobile phone use and daytime sleepiness in California high school students," BMC Public Health, 13, 840-845, 2013.

[35] Kawabata, F. and Tsuji, T, "Effects of dietary supplementation with a combination of fish oil, bilberry extract, and lutein on subjective symptoms of asthenopia in humans," Biomedical Research, 32(6), 387-393, 2011.

[36] Miljanović, B., Trivedi, KA., Dana, MR., Gilbard, JP., Buring, JE. and Schaumberg, DA, "Relation between dietary n-3 and n-6 fatty acids and clinically diagnosed dry eye syndrome in women," The American Journal of Clinical Nutrition, 82(4), 887-893, 2005.

[37] Yagi, A., Fujimoto, K., Michihiro, K., Goh, B., Tsi, D. and Nagai, $\mathrm{H}$, "The effect of lutein supplementation on visual fatigue: a psychophysiological analysis," Applied Ergonoomics, 40(6), 10471054, 2009.

[38] Nakaishi, H., Matsumoto, H., Tominage, S. and Hirayama, M, "Effects of black currant anthocyanoside intake on dark adaptation 
and VDT work-induced transient refractive alteration in healthy human," Alternative Medicine Review, 5(6), 553-562, 2000.

[39] Ma, L. and Lin, XM, "Effects of lutein and zeaxanthin on aspects of eye health," Journal of the Science of Food and Agriculture, 90(1), 2-12, 2010.

[40] Esteve Taboada, JJ., Del Águila Carrasco, AJ., Bernal Molina, P., Ferrer Blasco, T., López Gil, N. and Montés Micó, R, "Effect of phenylephrine on the accommodative system," Journal of Ophthalmology, 2016, 1-13, 2016.

[41] Hashimoto, H., Arai, K., Hayashi, S., Okamoto, H., Takahashi, J., Chikuda, M. and Obara, Y, "Effect of astaxanthin on accommodation, critical flicker fusion, and pattern visual evoked potential in visual display terminal workers," Journal of Traditional Medicine, 19(5), 170-173. 2002.
[42] Nagaki, Y., Mihara, M., Tsukuhara, H. and Ohno, S, "The supplementation effect of astaxanthin on accommodation and asthenopia," Journal of Clinical Therapeutics \& Medicines, 22(1), 41-54, 2006.

[43] Subbotina, A., Ravna, AW., Lysaa, RA., Abagyan, R., Bugno, R. and Sager, G., "Inhibition of PDE5A1 guanosine cyclic monophosphate (cGMP) hydrosing activity by sildenafil analogues that inhibit cellular cGMP efflux," Journal of Pharmacy and Pharmacology, 69(6), 675-683, 2017.

[44] Kamikawatoko, S., Tokoro, T., Ishida, A., Masuda, H., Hamasaki, H., Sato, J. and Azuma, H, "Nitric oxide relaxes bovine ciliary muscle contracted by carbachol through elevation of cyclic GMP," Experimental Eye Research, 66(1), 1-7, 1998. 